\title{
What U.S. Data Should be Used to Measure the Price Elasticity of Demand for Alcohol?*
}

\author{
Christopher J. Ruhm ${ }^{*}$, Alison Snow Jones $\ddagger$, Kerry Anne McGeary $\ddagger \ddagger$, William C. Kerr \\ Joseph V. Terza ${ }^{\ddagger \neq \neq \ddagger}$, Thomas K. Greenfield ${ }^{\ddagger \ddagger}$, and Ravi S. Pandian ${ }^{\ddagger}$ \\ ¥Department of Health Management \& Policy, Drexel University, Philadelphia, PA 19102 \\ ¥¥Department of Economics and Global Health Institute, Ball State University, 2000 W. University \\ Ave., Muncie, IN 47306 \\ ¥¥¥Alcohol Research Group, Public Health Institute, Emeryville, CA 94608-1010 \\ \#¥¥Department of Economics, Indiana University - Purdue University Indianapolis, Indianapolis, \\ IN 46202
}

\begin{abstract}
This paper examines how estimates of the price elasticity of demand for beer vary with the choice of alcohol price series examined. Our most important finding is that the commonly used ACCRA price data are unlikely to reliably indicate alcohol demand elasticities-estimates obtained from this source vary drastically and unpredictably. As an alternative, researchers often use beer taxes to proxy for alcohol prices. While the estimated beer taxes elasticities are more stable, there are several problems with using taxes, including difficulties in accounting for cross-price effects. We believe that the most useful estimates reported in this paper are obtained using annual Uniform Product Code (UPC) "barcode" scanner data on grocery store alcohol prices. These estimates suggest relatively low demand elasticity, probably around -0.3 , with evidence that the elasticities are considerably overstated in models that control for beer but not wine or spirits prices.
\end{abstract}

This paper examines how estimates of the price elasticity of demand for beer vary with the choice of alcohol price series used. The analysis is motivated by the apparent effectiveness of price related policies (mainly taxation) in reducing both alcohol consumption and the negative social costs associated with high levels of drinking (Giesbrecht et al, 2004; Cook, 2007; Chaloupka et al, 2002). We focus on beer because it is the most important source of alcohol, constituting roughly 55\% of ethanol consumed (NIAAA, 2010).

An enormous body of empirical research examines the price elasticities of demand for alcohol, and the consequences of such price changes for outcomes such as motor vehicle fatalities, binge drinking, and alcohol related violence.1 Understanding the responsiveness

\footnotetext{
* Support for this research by a grant from the National Institute on Alcohol Abuse and Alcoholism (R01AA017890) is gratefully acknowledged. We wish to thank Deidre Patterson, Keshia Maughn, Ian Reid, and Daniela Zapata for outstanding assistance with this research.

(C) 2012 Elsevier B.V. All rights reserved.

${ }^{* *}$ Corresponding author: Frank Batten School of Leadership and Public Policy, University of Virginia, 204 Garrett Hall, P.O. Box 400893, Charlottesville, VA 22904-4893.

Alison Snow Jones (Deceased)

Publisher's Disclaimer: This is a PDF file of an unedited manuscript that has been accepted for publication. As a service to our customers we are providing this early version of the manuscript. The manuscript will undergo copyediting, typesetting, and review of the resulting proof before it is published in its final citable form. Please note that during the production process errors may be discovered which could affect the content, and all legal disclaimers that apply to the journal pertain.
} 
of drinking, and its consequences, to price is important both for its own sake and because of the information provided on the potential effectiveness of price versus non-price policies. 2

Unfortunately, there are reasons to doubt the elasticity estimates obtained in prior studies, because of the difficulties in correctly defining and measuring the relevant prices of alcohol. One issue, which we will not try to resolve in this paper, is that single measures of beer, wine and spirits prices are generally used, even though consumers have incentives to substitute towards cheaper beverages in a given class when relative prices shift. Putting this aside, there are substantial difficulties in accurately measuring alcohol prices that have been largely ignored in previous research, raising doubts about the elasticity estimates obtained.

Many prior U.S. investigations (e.g. Kenkel, 1993; Sloan et al, 1994; Manning et al, 1995; Grossman et al, 1998; Williams et al, 2005; Arcidiacono et al, 2007) used alcohol prices from the ACCRA Cost of Living Index, a quarterly publication originally compiled by the American Chamber of Commerce Research Association and, since 1998, by the Council for Community and Economic Research. A principal advantage is that ACCRA provides prices for 120 to 300 medium and large cities, thus supplying one of the few sources of geographic data more detailed than the state level.3 However, the ACCRA data are subject to significant measurement error, potentially yielding imprecise and biased elasticity estimates (Young \& Bielinska-Kwapisz, 2003; Dave \& Kaestner, 2002). A primary shortcoming is that prices are collected for just one brand of beer, wine and blended whiskey, introducing considerable error if these brands do not reflect the purchases of "typical" drinkers or subgroups of particular interest (e.g. youths). In addition, ACCRA stopped collecting spirits prices after 2004.4

Given these problems, some researchers instead use beer taxes to proxy price variations (e.g. Chaloupka et al, 1993; Ruhm, 1996; Freeman, 2000; Markowitz et al, 2005). Taxes have at least two advantages: they are directly amenable to policy interventions (i.e. state and national alcohol taxes are set by governments) and they are determined independently of demand, whereas prices need not be. However, taxes present other issues. First, it is difficult to determine the tax on distilled spirits and wine in "control" states, where sales occur only through state liquor stores.5 One result is that the aforementioned investigations control just for beer taxes and not also those on wine and spirits. Second, state taxes constitute only a small share ( 3 to 5 percent) of retail alcohol prices. Third, since states change excise taxes relatively infrequently, most of the temporal variation in real rates is due to inflation rather than changes in nominal taxes. Finally, taxes may be endogenously determined. For instance, high taxes in states with strong anti-drinking sentiments would introduce a spurious negative correlation between alcohol taxes and use.

\footnotetext{
${ }^{1}$ A meta-analysis of 112 studies by Wagenaar et al. (2009) finds that average reported price elasticities are -0.46 for beer, -0.69 for wine and -0.80 for spirits. However, most investigations (e.g. 40 of 47 studies of beer consumption) use aggregate data, which tend to yield larger (absolute values of) elasticities than analyses using individual data-in part because of cross-border purchases whereby purchases occur in jurisdictions with lower prices. An earlier review by Leung \& Phelps (1993) estimates consensus beer, wine and spirits elasticities of $-0.3,-1.0$ and -1.5 . Chaloupka et al. (2002) review the literature examining how prices are related to drinking and related alcohol problems (motor vehicle crashes, health, violence and crime) among youths and young adults.

${ }^{2}$ Examples of non-price policies include minimum legal drinking ages, drunk driving penalties, and alcohol availability constraints (e.g., see Giesbrecht \& Greenfield, 2003)

${ }^{3}$ The number of cities varies by year. Cities with populations of at least 50,000 are eligible for inclusion, although some smaller cities were "grandfathered" in when the population criteria were originally established. Information on the ACCRA data is available at: http://coli.org/.

${ }^{4}$ Additional problems are that prices in discount outlets are specifically excluded and that the collectors of ACCRA prices are not specifically trained as data gatherers.

${ }^{5}$ There are 18 such states for spirits and five for wine. This paragraph draws heavily on a detailed discussion in Young \& BielinskaKwapisz (2002).
} 
For these reasons, we compare elasticity estimates obtained using ACCRA prices and beer taxes to those using an alternative source of price data - annual Uniform Product Code (UPC) or "barcode" scanner data, collected by AC Nielsen. The UPC data offers detailed and precise information on alcohol sales for detailed geographic markets and, using these data, we calculated the total value of sales (in dollars) and volume of sales, by brand and beverage type, for beer, wine, and spirits sold in grocery stores in 45, 36 and 21 markets respectively. 6

Although superior to other sources of price information, the scanner data have limitations. First, the Nielsen markets tend to represent densely populated areas that correspond to one or more Standard Metropolitan Statistical Areas (SMSA). Consequently, UPC data are not available for some rural locations, including the entire states of Montana, the Dakotas, and Maine. Second, the data are unavailable for liquor stores or other sellers of alcohol (such as Costco and Walmart), and for control states that restrict alcohol sales in supermarkets.7 To reduce the effect of the last exclusion, missing UPC wine and spirit prices in the control states were supplemented with brand-level price (and sales) information from the National Alcohol Beverage Control Association's (NABCA) Statistics for Alcohol Management (SAM) database.

Rather than relying on general measures of alcohol sales as dependent variables in our beer consumption models, we obtain detailed information on drinking from the first and second waves of the National Epidemiological Survey of Alcohol and Related Conditions (NESARC 1 and 2), conducted in 2001-02 and 2004-05 respectively. These national surveys were sponsored by the National Institute on Alcohol Abuse and Alcoholism and are designed to provide nationally representative estimates of alcohol consumption, abuse and dependence for non-institutionalized adults aged 18 and older.8

We utilize two basic analysis strategies. First, we examine whether elasticity estimates obtained with the commonly used ACCRA data are robust to the years over which alcohol prices or drinking are measured, and the geographic area of analysis. Second, we investigate the sensitivity of the estimated consumption elasticities to: 1) the use of alternative price series (ACCRA, beer taxes or UPC prices), measured in a given year; 2) the geographic area of analysis; and 3) the inclusion of additional controls for wine and distilled spirits prices.

Our most important finding is that demand elasticities obtained using ACCRA prices are extremely unstable, with plausible specifications providing results consistent with either no or extremely large responsiveness of beer consumption to prices. This suggests that the results of previous research, using ACCRA data, are unreliable and sensitive to both the choice of data years and estimation samples. We also provide a rudimentary test of whether the same problems apply to longitudinal analyses identified by within-locality changes in ACCRA prices and obtain implausibly large elasticity estimates, which may occur because measurement error is particularly problematic in fixed-effect models. 9 The results further suggest that estimates of demand elasticities are attenuated when using taxes, rather than

\footnotetext{
${ }^{6}$ UPC data have previously been used in alcohol-research by Bray et al. $(2007,2009)$. UPC data on sales in convenience stores were available in 19 markets for 2008 (but not 2004, the year we analyze). Using 2008 data, we confirmed a strong relationship between UPC grocery store and convenience store beer prices - the correlation was 0.92 , with an average difference of 8 cents per ounce of ethanol. The number of markets is smaller for wine and spirits than for beer because some states allow grocery store sales of beer, but not wine or spirits. We also exclude from our analysis the five states (Utah, Colorado, Minnesota, Kansas and Oklahoma) where grocery stores are not permitted to sell beer with an alcohol content exceeding $3.2 \%$ alcohol by weight.

${ }^{7}$ Supermarkets account for around $40 \%$ of beer sales (Bray, et al., 2007).

${ }^{8}$ See http://aspe.hhs.gov/hsp/06/catalog-ai-an-na/nesarc.htm for general information on the NESARC surveys and Grant et al. (2003), Chen et al. (2006) or Dawson et al. (2007) for detailed discussions and examples of analysis.

${ }^{9}$ We have not examined the effects of instrumenting ACCRA prices with taxes, as has been done by Young \& Bielinska-Kwapisz (2003). However, as discussed, this is likely to be particularly problematic when using taxes to instrument spirits prices.
} 
direct measures of prices, but these findings are less definitive, in part because of the inherent shortcomings of the tax data previously discussed. We conclude that there are benefits from using more detailed price information, such as the scanner data that we employ.

\section{National Epidemiological Survey of Alcohol and Related Conditions}

Information on alcohol use and personal characteristics are obtained from the first and second waves of the National Epidemiological Survey of Alcohol and Related Conditions. Collection of the NESARC 1 data occurred in 2001-02 (with around 85 percent of interviews in 2001). The follow-up NESARC 2 survey took place in 2004-05 (with 82 percent of interviews in 2004). The timing of the surveys is relevant since we can only match the UPC price data to NESARC 2, whereas ACCRA prices can be attached to both NESARC 1 and NESARC 2.10 Since the ACCRA and UPC information are unavailable for rural areas and small towns, we restrict analysis to NESARC respondents in metropolitan areas.

The NESARC contains detailed information on alcohol use (including the types of beverages consumed), abuse and dependence; treatment for alcohol problems; and family history of alcoholism or mental illness. The goal of the current project is to use relatively straight-forward models to investigate whether estimates of average alcohol demand elasticities are sensitive to the price measures employed. We examine two dimensions of alcohol use-whether the individual has drunk beer during the previous 12-month period, and the quantity of beer consumed - and implement the alcohol demand elasticity estimation method suggested by Manning et al. (1995), which is based on the conventional two-part modeling approach and designed to accommodate both of these two salient aspects of alcohol use. The analysis focuses on ethanol equivalent ounces of beer consumption, using procedures detailed below.

The NESARC data also allow us to control for supplementary demographic characteristics related to: sex, marital status, race/ethnicity (black, Hispanic, other non-Hispanic nonwhite), family size, education (less than high school graduate, some college), occupation (blue collar, white collar, service), geographic region (Midwest, South, West), and household income. 11

\section{Alcohol Prices and Sample Construction}

ACCRA prices for beer, wine, and spirits were obtained annually for 2000-2004. As mentioned, these data are limited to one brand for each type of alcohol.12 We calculated ethanol equivalent prices per ounce of alcohol using information on the alcohol content of the respective beverages obtained from a variety of sources.13 ACCRA prices were next linked to counties using geographic tables obtained from the census and assigned a population weight (for persons 15 years and older). Weighted State and UPC market prices were then calculated from these county-level values.

\footnotetext{
${ }^{10} \mathrm{We}$ do not utilize the longitudinal nature of the two waves of the NESARC.

${ }^{11}$ Household income refers to money received by all household members from: jobs, self-employment, Social Security, Railroad Retirement, SSI, Veterans payments, retirement/disability/survivor pensions, interest, dividends, workers compensation, unemployment insurance, child support, alimony, educational assistance (tuition, books, living expenses), and public assistance (AFDC, ADC, WIC or any other public assistance/welfare payments).

${ }^{12}$ In the years studied, data were provided for six packs (12 ounce containers) of Heineken (beer), 1.5 liter bottles of Gallo or Livingston Cellars Chablis (wine) and $750 \mathrm{ml}$ bottles of J\&B Scotch (spirits).

13 These included information provided in the UPC data and the NABCA database for spirits, and liquor control board price lists from Washington and Pennsylvania for wine. Beer data were obtained from the Kansas Department of Revenue (https://www.kdor.org/ brands/default.aspx), manufacturer websites (e.g. www.millercoors.com/our-beers), and other related websites such as the Beer Advocate (www.beeradvocate.com).
} 
Uniform Product Code (UPC) scanner data on alcohol prices were obtained from AC Nielsen. These data were collected from grocery stores in 51 markets with annual sales in excess of $\$ 2$ million although, as mentioned, we exclude the markets in the 5 states which do not permit supermarket sales of beer with alcohol content greater than $3.2 \%$ ABW. Figure 1 provides an example of the type of information available for a single market (Buffalo-Rochester) and beverage type (Budweiser beer). Conversion of the UPC data to price per ounce of ethanol involved several steps. First, volume was expressed in "equivalent units" to account for differences in packaging sizes—-for instance, beer could be sold as single bottles (of varying sizes), six packs, 12 packs, or cases.14 Next, the percent alcohol by volume (\% ABV) was calculated for each beer, wine and spirits brand.15 Multiplication of \%ABV by number of ounces in each package size yielded total ounces of ethanol, which price was then divided by.

Sales volume weights were then used to obtain a single "average" price for the specified beverage type (beer, wine and spirits) in each market.16 These prices were aggregated to the state level, using county population when there were multiple markets in the state. Analysis was restricted to NESARC residents of urban and suburban areas in states with price data.

The estimation sample varies across models, with an effort made to estimate some specifications using the widest geographic area for which the specified price data are available, and to provide comparability of estimates with models that utilize more restricted geographic samples. Specifically, for analyses focusing on ACCRA prices, the sample includes the 41 states for which we were able to obtain ACCRA beer, wine and spirits prices throughout the 2000-2004 period.17 When estimating models for 2004 only, we have ACCRA prices for 44 states, our most comprehensive sample. 18 We are able to match ACCRA and UPC beer (but not wine or spirits) prices for 35 states and ACCRA beer, wine and spirits prices with corresponding UPC prices for 25 states. 19 Therefore, we estimate models on all of these samples, when comparing results using ACCRA and scanner prices. We have information on beer taxes for all states and so estimate tax models, using samples with 25,35 and 44 states.

Table 1 presents descriptive statistics for all respondents and for beer consumers for the 25 , 35 and 44-state NESARC 2 samples. Respondent characteristics are similar across samples, except that the West and Midwest are over-represented in those with fewer states. Beer drinkers are disproportionately male, non-Hispanic white, college educated, and high income.

\footnotetext{
${ }^{14}$ Beer sold in kegs, half kegs, and quarter kegs were excluded from these calculations, although nearly identical average prices were obtained when they were included. Wines were restricted to the following categories: Imported Dry Table, Domestic Dry Table, Flavored Refreshment, and Sparkling.

${ }^{15}$ We were not able to determine \%ABV from external sources for 269 out of 500 beers. However, these comprised only $0.9 \%$ of total beer sales across the 51 Nielsen markets. For these beers, we estimated \% ABV from a regression of \% ABV on price, package size, beer type (Ice, Pale, Amber, Dark, Pilsner, etc.), higher order terms, interactions, and market fixed effects. Wine, ABV values were obtained for 314 (out of 6489) different brands, accounting for 57\% of the wine sold in the UPC records. For the remaining brands, an average \% ABV was assigned based on the wine type (chardonnay, pinot noir, etc.). For spirits, the UPC and NABCA sales records contained a proof value, permitting direct calculation of ethanol content.

${ }^{16}$ The average prices used here do not account for substitution towards less expensive products when relative prices change. Such potential substitution bias is also present in previous investigations.

${ }^{17}$ Details on the states included in the various specifications are contained in the table notes. Pennsylvania is excluded for reasons discussed below.

${ }_{18}^{18}$ Pennsylvania is again excluded.

${ }^{19}$ We have scanner data for fewer states because the UPC markets do not include spirits in many states and since we do not have beer prices in some of the control states where spirits prices are available.
} 


\section{Analytic Methods}

Previous researchers (e.g. Coate \& Grossman, 1988; Grossman et al. 1987; Leung \& Phelps, 1993; Laixuthai \& Chaloupka; 1993 Kenkel, 1996; Farrell, Manning \& Finch, 2003; Manning et al, 1995) employ models derived from economic theory in which a utilitymaximizing consumer allocates income to purchase goods and services subject to preferences, market prices, and other determinants of demand. Because income is a binding constraint in the short-run, the consumer's only option in responding to price changes is to alter the mix of goods and services purchased, conditioned on preferences and other demand determinants (e.g. availability). This leads to substitution away from more costly goods as relative prices change. With additional assumptions, this framework yields functional relationships between quantity demanded and relevant prices, income, other individual traits, and market characteristics:

$$
A_{j}=A_{j}\left(P_{j}, P_{\neq j}, Y, X\right)
$$

Where $\mathrm{A}_{\mathrm{j}}$ is the quantity of alcoholic beverage $j$ demanded ( $\mathrm{j}=\mathrm{BEER}$, WINE, SPIRITS), $\mathrm{P}_{\mathrm{j}}$ denotes the real price of beverage $j, P_{A}$ denotes the vector of prices for the other alcoholic beverages (not $\mathrm{j}$ ), $\mathrm{Y}$ is income, and $\mathrm{X}_{\mathrm{j}}$ is a vector of demand shifters for beverage $\mathrm{j}$ (e.g., age, race, gender, and education).

We estimate the elasticity of beer consumption using a two-part framework comprising distinct model components representing: 1) any beer consumption - the hurdle component (a binary variable); and 2) the natural $\log$ of the quantity of beer consumed conditional on drinking - the levels component.20 Following Manning et al. (1995), we estimate the price elasticity of demand for beer from this model as:

$$
\hat{\eta}_{\text {BEER }}=(1-\hat{\mathrm{H}}) \hat{\beta}_{\mathrm{BEER} 1}+\hat{\beta}_{\mathrm{BEER} 2}
$$

where $\hat{\mathrm{H}}$ is the estimated proportion of the sample having non-zero beer consumption, $\hat{\beta}_{\text {BEER1 }}$ denotes the coefficient of log-price in the hurdle part of the model (corresponding to whether or not any beer is consumed-the extensive margin), and $\hat{\beta}_{\mathrm{BEER} 2}$ is the estimated coefficient of log-price in the levels part (corresponding to beer consumed at the intensive margin). Note also that

$$
\hat{\eta}_{\mathrm{BEER}(1)}=(1-\hat{\mathrm{H}}) \hat{\beta}_{\mathrm{BEER} 1}
$$

the first additive component on the right-hand side of (2), represents the contribution of the extensive margin to the overall price elasticity. Our methods of calculating asymptotic standard errors for the elasticities specified in (2) and (3) are detailed in appendix A.

\section{Comparison of ACCRA and UPC Prices}

As discussed, ACCRA data contain information for only a single brand of beer, wine and spirits. Since these brands are not representative of the "average" purchase, they poorly proxy the relevant prices. To demonstrate that this concern is salient, we calculated the per ounce ACCRA and UPC prices of ethanol, averaged across all available markets.21 ACCRA beer prices averaged $\$ 2.06$ per ounce of ethanol, which is 69 percent higher than corresponding weighted UPC beer price (\$1.22). This was expected since ACCRA prices

\footnotetext{
${ }^{20}$ The two-part model allows the data generating process underlying the drinking participation decision to systematically differ from the process determining the level of alcohol consumed by participants.

${ }^{21}$ Here and throughout the analysis, UPC sales represent volume-adjusted prices from actual grocery store purchases, implying that the most heavily consumed brands and types receive the greatest weight in the price calculations.
} 
are for high-priced Heineken beer. Similarly, mean ACCRA spirits prices were 97 percent above UPC prices (\$2.07 vs. \$1.05), because ACCRA collected data on J\&B Scotch, a relatively expensive brand of distilled spirits. Conversely, since ACCRA measures prices of the non-premium Gallo or Livingston Cellars Chablis wine, average ACCRA wine prices were 42 percent below corresponding UPC prices (\$1.07 vs. \$1.83).

These disparities suggest that estimates exploiting geographic variations in ACCRA prices may be biased, unless the ratio of ACCRA to UPC prices is similar across markets.22 Even if they are, ACCRA will not correctly indicate the relative prices across beverage types, so that the estimated cross-price elasticities will almost certainly be inaccurate. For example, the UPC data indicate that alcohol from beer is almost one-third cheaper than that from wine, on average, whereas ACCRA prices misleadingly indicate that ethanol from beer costs nearly twice as much.

Figures 2a through 2c provide corresponding market-specific comparisons of average 2004 UPC and ACCRA prices per ounce of ethanol for beer, spirits, and wine.23 The dotted lines indicate regression estimates of UPC prices on ACCRA prices.24 The patterns observed when aggregating across all markets-higher ACCRA than UPC prices for beer and spirits but lower ACCRA prices for wine-are present in each individual markets. However, the ratio of ACCRA to UPC prices varies substantially. For instance, the ACCRA beer price is 96, 96 and 93 percent above the UPC level in Charlotte, Cleveland and Cincinnati, but just 45, 47 and 48 percent greater in Washington DC, Dallas and San Francisco.25 ACCRA spirit prices are 144 and 120 percent greater than UPC prices in Milwaukee and Tampa, compared to 33 and 66 percent higher in Boston and New Orleans/Mobile. ACCRA wine prices are 53, 52 and 51 percent below UPC prices in San Diego, Des Moines, and Seattle versus 22, 25, and 30 percent lower in Las Vegas, St Louis and Boston. Generally, ACCRA prices are fairly weak predictors of UPC prices. 26

\section{ACCRA Data Do Not Provide Robust Elasticity Estimates}

Estimates of the price elasticity of demand for beer obtained using cross-sectional ACCRA prices are sensitive to the time period chosen for analysis. To show this, we estimated elasticities using NESARC 1 (collected in 2000-2001) with ACCRA prices from 2001, as well as from NESARC 2 data (collected over 2004-2005) with 2004 ACCRA prices. The 2001 and 2004 ACCRA data control for contemporaneous prices for a majority of NESARC $1(85 \%)$ and NESARC $2(82 \%)$ respondents. Columns (a) and (b) of Table 2 show results for our base sample consisting of NESARC 1 and NESARC 2 respondents from metropolitan areas in 41 (non-3.2\% ABW) states for which ACCRA beer, wine and spirits prices were available in 2001 and 2004. Columns (d) and (e) add observations for Pennsylvania, the one additional state for which we have the necessary data, as discussed below.

\footnotetext{
${ }^{22}$ To the extent that the ratio of ACCRA to UPC prices is similar, the price differences will be incorporated into the intercept term in the regression estimates, although the elasticity estimates (which reflect percentage changes from the base price) could still be affected.

${ }^{23}$ Several states (NY, FL, TX, CA, OH and NC) contain more than one Nielsen market.

${ }_{25}^{24}$ These are unweighted estimates that assign an equal value to each market.

25 In preliminary research, we compared grocery store beer prices (used in the regressions below) to those for sales in convenience stores, for the 19 markets where the latter were available. Prices were typically slightly lower in convenience than grocery stores (\$5.94 versus \$6.21 per six pack and \$1.39 versus \$1.44 per ounce of ethanol) but much lower in either case than ACCRA measured prices (\$7.98 per six pack and $\$ 2.25$ per ounce of ethanol).

${ }^{26}$ The coefficient estimates from regressing UPC and ACCRA prices are $0.38,0.53$, and 0.27 for beer, spirits, and wine. For spirits, the coefficient falls to 0.34 if we exclude one market (Boston) which has by far the highest UPC prices and also relatively high ACCRA prices.
} 
If ACCRA prices are useful, we expect to obtain similar elasticity estimates across the two surveys, however, this is not the case. Estimates of the own price elasticity of total beer consumption are -1.8 in column (a) using the NESARC 1, versus -3.2 in column (b) using the NESARC 2 data from three years later (see the top panel of Table 2). Similarly, the estimated elasticity of drinking participation, shown in the lower panel, is 60 percent larger for NESARC 2 than NESARC 1 ( -1.4 vs. -0.9$)$, and the cross price elasticities vary dramatically across years, particularly for wine prices.

The sensitivity of the cross-sectional estimates obtained when using ACCRA prices can be further demonstrated by adding one state, Pennsylvania, to the analysis sample. As discussed, ACCRA beer price data are collected for six-packs of Heineken beer. In this regard, Pennsylvania poses a particular problem because retail beer can only be purchased from restaurants, bars, licensed beer stores, or beer distributors. Beer distributors, the primary point of purchase, mainly supply cases and kegs, not smaller volumes such as six packs. Bars, restaurants, and licensed retailers are permitted to sell six and twelve packs (or individual bottles in sizes such as 24 or 40 ounces), with sales restricted to a maximum of 192 ounces of beer per purchase per person (Pennsylvania Liquor Control Board, 2011). These restrictions allow small volume suppliers to charge a premium for the limited quantities and create a situation where most beer purchases are made by the case (from distributors) rather than the six-pack. One result is that the ACCRA beer prices for Pennsylvania will be much higher than typical prices for beer purchased there. 27

The fourth and fifth columns of Table 2 show that adding respondents from Pennsylvania dramatically attenuates the estimated total demand elasticities-by almost 90 percent when using NESARC 1 and more than half for NESARC 2. Although the ACCRA prices in Pennsylvania are likely to be particularly problematic, similar issues are likely to be present in previous investigations using the ACCRA data to estimate price elasticities, since most researchers have not conducted a systematic state-by-state analysis of the appropriateness of the price data.

As a further check, we also estimated beer consumption elasticities using a panel consisting of the combined NESARC 1 and 2 data, with ACCRA prices from 2001 and 2004, and with state fixed-effects controlled for. These results are summarized in columns (c) and (f), respectively, for samples without and with data from Pennsylvania. As might be expected if the fixed-effects account for the unusual institutional environment in Pennsylvania, the panel estimates are robust to its inclusion in the sample. However, the elasticities estimates are implausibly large: -4.4 to -4.6 for total beer consumption and -1.5 for beer drinking participation. Thus, ACCRA prices do not appear to provide useful estimates even with longitudinal data.

The bottom line is that, when using the ACCRA data, relatively minor changes in the time period of analysis or sample inclusion criteria provide such a wide variation of elasticity estimates as to provide little useful guidance for policy-makers. Specifically, the estimates in Table 2 suggest that the price elasticity of total beer demand (beer drinking participation) ranges from -0.2 to $-3.2(-0.2$ to -1.4$)$, or even higher for the panel estimates. At the lower end of the range we are unable to reject the null hypothesis of no price effect, while the larger estimates suggest that beer demand is extremely price-elastic.

${ }^{27}$ Given this it is no surprise that 2004 ACCRA beer prices were outliers for most Philadelphia markets (Johnstown, Philadelphia, York County, Lebanon, Williamsport and Harrisburg). Interestingly, ACCRA prices were considerably lower, and within the range of non-Pennsylvania markets, in Pittsburgh. 
The shortcomings of estimates obtained using the ACCRA data are even more serious than they at first appear. We have argued that Pennsylvania prices are particularly problematic, suggesting that cross-sectional estimates will be improved by excluding observations from this state (and potentially others with similar issues). Doing so would lead to relatively high elasticity estimates (e.g. -1.8 to -3.2 for total beer consumption). However, as shown below, these magnitudes are much larger than those obtained using either beer taxes or the more reliable UPC price data.

\section{Elasticity Estimates are Sensitive to Changes in Samples and Sources of Price Data}

This section examines whether the estimated price elasticity of demand for beer is sensitive to the choice of price series and samples. For this analysis, we face several data restrictions. First, we have 2004 ACCRA data on beer, wine and spirits prices for 44 states; (excluding observations for Pennsylvania, for the reasons discussed above) however, Nielsen collects corresponding grocery store scanner prices for markets in only 35 of these states. Second, because some states restrict distilled spirits sales to state liquor stores, the UPC data containing spirits and wine prices is limited to 25 states. Third, since wine and spirits tax rates are complicated to calculate in the control states, we follow previous research in by estimating tax models that control for beer taxes only, although we also show that the failure to control for cross-price effects is likely to be problematic, and represents a shortcoming of such specifications. Given these issues, we provide results from a comprehensive set of models with alternative sampling criteria and price/tax controls. Since the UPC data were unavailable to us prior to 2004, all specifications control for 2004 prices or taxes, with consumption measured using the NESARC 2.28

Table 3 summarizes the findings. The top panel again shows estimates for total demand elasticities and the bottom one provides elasticities of drinking participation. From a theoretical perspective, it is always desirable to control for wine and spirits prices, as well as those for beer, but the data do not permit this for the 35-state sample with UPC prices, or when using tax data. Therefore, wine and spirits prices are controlled for only in columns (b), (d), (f) and (h), with the immediately preceding columns showing results for corresponding models that exclude these additional price controls. Models with ACCRA prices, columns (a) through (f), are estimated with and without controls for wine and spirits prices and for the 25, 35 and 44 state samples. Specifications with UPC prices, columns (g) through (i), are estimated with and without wine and spirits prices for 25 states and with beer prices only for 35 states. Beer tax models, columns (j) through (l), are estimated for the 25 , 35 and 44 state samples but do not include wine or spirits taxes. All specifications also control for the full set of demographic and geographic characteristics (shown in Table 1).

Columns (a) through (f) provide further evidence of the sensitivity of the estimated beer demand elasticities to the states included in the sample, when using ACCRA prices (even when Pennsylvania is excluded, as it is throughout the table). When wine and spirits prices are also controlled for, the estimated elasticity is attenuated from -3.8 in the 25 state sample (column b) to -3.3 for 35 states (column d) and -2.7 with 44 states are included (column f). Although wider geographic variation is presumably preferable, even the smaller sample contains many large states (including California and Florida) and the 35 state sample includes all of the five largest states, so that the sensitivity of the results would be somewhat unexpected if ACCRA prices were useful for this analysis.

\footnotetext{
${ }^{28}$ Although ACCRA and UPC beer prices are positively correlated for the 35 state sample $(\mathrm{r}=0.37)$, beer taxes are insignificantly negatively associated with both UPC and ACCRA beer prices (the correlation coefficients are -0.06 and -0.13 respectively).
} 
In addition, much larger, own price elasticities are obtained using ACCRA prices than with either UPC prices or beer taxes. For instance, using the 25 state model with controls for wine and spirits prices, the elasticity of total beer consumption is estimated to be -3.8 with ACCRA prices (column b) versus a statistically insignificant -0.3 with UPC prices (column h). This runs counter to the expectation that classical measurement error will lead to attenuated estimates when using (error-prone) ACCRA prices (Wooldridge, 2010, p. 80). However, in this application the measurement error is unlikely to be classical (i.e. uncorrelated with the true price) because ACCRA prices are based on a single high-priced brand (Heineken). If these prices are relatively high and stable across observations compared to the true average price for a sampled unit (e.g. the UPC price), there will probably be a negative correlation between ACCRA prices and the true price. We show in Appendix B that elasticity estimates may be upward biased (in absolute value) in the presence of such non-classical negatively correlated measurement error.

Using UPC beer prices, but without controls for wine and spirits prices, the total own price elasticity of beer demand is around -1.0 (see columns $g$ and i) and relatively insensitive to expanding the sample from 25 to 35 states, while the point estimate on the elasticity of drinking participation is attenuated from -0.55 to -0.34 . More significantly, the magnitude of the total beer demand elasticity in the 25 state sample (the only one where we can include cross-price effects) declines by more than two-thirds - to around - 0.3 - when wine and spirits prices are also controlled for, and all of the remaining responsiveness to price occurs at the extensive margin (column h). These estimates suggest two conclusions. First, much smaller elasticities are obtained when using actual prices paid at supermarkets than with the less accurate ACCRA prices. Second, it is important to also control for wine and spirits prices, since the own price elasticities are likely to be overstated when this is not done.

Tax elasticities of total beer consumption are always close to zero and statistically insignificant, as shown in columns (j) through (1). Interestingly, higher taxes may have a small negative effect on beer drinking participation - the estimated elasticity is -0.04 or -0.05 - which is offset by an imprecisely estimated positive effect at the intensive margin. 29 As with the UPC data, but in contrast to the models controlling for ACCRA prices, the elasticity estimates are unaffected by changing the number of states sampled. However, cross-sectional estimates may be particularly problematic in the case of beer taxes, since these may be endogenously correlated with other determinants of drinking and because of the difficulty in also controlling for potentially important wine and spirit cross-price effects.

Finally, the estimated income elasticities are extremely stable across specifications and sources of price data, and imply that beer drinking is a normal good with income effects concentrated at the extensive margin. The UPC also data show that beer is a complement to wine and spirits, whereas the ACCRA data suggest that beer drinking is largely unrelated to the prices of other types of alcohol. The coefficient estimates on the supplemental demographic and geographic covariates are also robust to changes in the estimation model.

\section{Discussion}

Our most important finding is that the commonly used ACCRA price data are unlikely to reliably indicate price elasticities of beer demand. Instead, these estimates differ drastically and unpredictably depending on the year examined and exact sample within a given year analyzed. In plausible specifications, we obtain point estimates of total own price beer elasticities varying between -1.8 and -3.9 , with considerable imprecision around even this wide range (and even larger elasticity estimates in fixed-effect models). When we expand

\footnotetext{
${ }^{29}$ The elasticity estimates (not shown) range from 0.04 to 0.08 , with standard errors between 0.04 and 0.06 .
} 
the sample to contain observations from Pennsylvania, which we argue are problematic but have generally been included by other researchers, the lower-range of the elasticity estimate falls to -0.2. Such sensitivity could easily explain discrepancies shown in the literature and, more importantly, suggests that the "sensible" elasticities obtained in much previous work may have occurred because researchers had the good luck to choose years and samples providing such estimates, or because extreme results were less often reported or published.

As an alternative, researchers have often used beer taxes to proxy for alcohol prices. However, since real beer tax rates have fallen dramatically over time-from $\$ 0.10$ per standard 12 ounce drink in 1960 to $\$ 0.03$ in 2010 (in 2011 dollars)-they constitute such a small share of prices that even a doubling or tripling of state beer taxes would probably not have much effect on consumption.30 In addition, cross-sectional variations in taxes may be dominated by difficult to control for confounding determinants of drinking. Either factor may explain why beer taxes are negatively correlated with both UPC and ACCRA prices for the years we study. Given this, it is not surprising that our estimated beer tax elasticities are close to zero, although there is some suggestion of a negative tax elasticity of drinking participation. Our estimates using the UPC data further suggest the importance of controlling for cross-price effects, but heroic efforts are needed to calculate tax rates on spirits (wine) in the 18 (5) states restricting such sales to state liquor stores. We attempted such computations but viewed the final estimates to be unreliable because they required such strong assumptions. 31

Given these issues, we believe that the most our most useful estimates are obtained using the detailed scanner data for grocery store purchases. These estimates suggest a relatively low price elasticity of demand for beer, probably around -0.3 , with evidence that responsiveness of consumption to price is considerably overstated in models that control for beer but not wine or spirits prices. We caution that these estimates are not without problems. Most importantly, using cross-sectional data, the elasticities will be understated if geographic variations in prices are dominated by demand factors that differ across markets. Our treatment of observed alcohol prices as being endogenous thus represents a strong and possibly problematic assumption, but also one shared by almost all previous related research.

A potential future research strategy would be to use longitudinal scanner price data to estimate models identified by within-market changes in prices. It would also be useful to employ such data to estimate demand elasticities for other types of alcohol, although the large number of beverage types (particularly for wine) increases the difficulty of calculating percent alcohol by volume when doing so. Our UPC price data were limited to grocery stores, underscoring the need for subsequent studies accounting for sales in liquor, convenience and warehouse stores, and for differences in prices for alcohol consumed in bars and restaurants versus that purchased for "off-premise" consumption. Finally, we have treated individuals as homogenous and so have calculated average price-elasticities of

\footnotetext{
${ }^{30}$ Using ACCRA prices, Young (2010) estimates that state taxes averaged 1.7 percent of the purchase price of beer and 4.4 percent of the price of wine in 2009, and 6.1 percent of the price of spirits in 2004.

${ }^{31}$ We initially attempted to calculate tax rates in these cases using the method of Benson et al. (2003), which compares prices for the same brands across open and control states. However, this assumes that control and open state wholesalers pay the same price to producers, which we determined was not the case for the control states where these data were available. As an alternative, we used the following procedure: 1) compute an average freight on board (FOB) price for specified types of alcohol (e.g. $750 \mathrm{ml}$ bottles) in a given year; 2) calculate the corresponding retail price in each control state utilizing that state's mark-up formula; 3) calculate the expected open state price using typical wholesale and retail mark-up percentages; 4) treat the difference between each calculated control state price and the expected open state price as a tax estimate that includes the typical open state mark-up (because the tax is levied before the wholesale mark-up); 5) remove this mark-up to get the tax estimate for each state. Obviously, this procedure makes an assumption about the typical mark-up at the wholesale and retail levels. Also, the tax estimates vary with the price of the beverage chosen since, assuming a constant percentage mark-up, the computed excise tax increases approximately proportionately with the assumed price in most states.
} 
demand. However, it is likely that the demand elasticities vary considerably across consumers in ways that are currently poorly understood.

\section{Appendix A}

\section{A.1 Asymptotic Standard Error and t-stat for the Overall Elasticity Estimator (2)}

Although not explicitly discussed by Manning et al. (1995), one can surmise that the price elasticity of beer demand estimated by (2) is

$$
\eta_{\mathrm{BEER}}=\mathrm{E}\left[\frac{\partial \ln \mathrm{E}\left[\mathrm{A}_{\mathrm{BEER}} \mid \ln \left(\mathrm{P}_{\mathrm{BEER}}\right), \mathrm{X}_{\mathrm{BEER}}\right]}{\partial \ln \left(\mathrm{P}_{\mathrm{BEER}}\right)}\right]
$$

where $A_{B E E R}$ denotes observed beer consumption, $\mathrm{P}_{\mathrm{BEER}}$ represents the price of beer, and $\mathrm{X}_{\mathrm{o}}=\left[\mathrm{P}_{\text {WINE}}, \mathrm{P}_{\text {SPIRITS }}, \mathrm{Y}, \mathrm{X}_{\mathrm{BEER}}\right]$ is the vector of observable control variables in the beer demand equation. Following Manning et al. (1995)

$$
\mathrm{E}\left[\mathrm{A}_{\mathrm{BEER}} \mid \ln \left(\mathrm{P}_{\mathrm{BEER}}\right), \mathrm{X}_{\mathrm{o}}\right]=\Lambda\left(\mathrm{X} \beta_{1}\right) \exp \left(\mathrm{X} \beta_{2}\right) \psi \quad(\mathrm{A}-2)
$$

where $\mathrm{X}=\left[\ln \left(\mathrm{P}_{\mathrm{BEER}}\right) \mathrm{X}_{\mathrm{o}}\right], \beta_{1}^{\prime}=\left[\beta_{\mathrm{BEER} 1} \beta_{\mathrm{o} 1}^{\prime}\right], \beta_{2}^{\prime}=\left[\beta_{\mathrm{BEER} 2} \beta_{\mathrm{o} 2}^{\prime}\right], \Lambda()$ denotes the logistic distribution function, $\psi$ is the smearing factor which is assumed to be constant,32 and the $\beta \mathrm{s}$ are parameters (and parameter vectors) to be estimated. Combining (A-1) and (A-2) we obtain

$$
\eta_{\mathrm{BEER}}=\mathrm{E}\left[\frac{\partial \ln \left(\Lambda\left(\mathrm{X} \beta_{1}\right) \exp \left(\mathrm{X} \beta_{2}\right) \psi\right)}{\partial \ln \left(\mathrm{P}_{\mathrm{BEER}}\right)}\right]=(1-\mathrm{H}) \beta_{\mathrm{BEERI}}+\beta_{\mathrm{BEER} 2}
$$

where $\mathrm{H}$ denotes the population proportion of beer drinkers - those for whom the hurdle component of the two-part model is equal to 1 , and $\lambda()$ is the logistic probability density function. The corresponding sample analog elasticity estimator is (2). Following Terza (2012), we can equivalently re-write (2) as

$$
\hat{\eta}_{\text {BEER }}=\sum_{\mathrm{i}=1}^{\mathrm{n}} \frac{1}{\mathrm{n}} \hat{\eta}_{\text {BEERi }} \quad(\mathrm{A}-4)
$$

where $\hat{\eta}_{\text {BEERi }}=\eta\left(X_{i}, \hat{\beta}\right)=\hat{\beta}_{\text {BEER } 1}-\Lambda\left(X_{i} \hat{\beta}_{1}\right) \hat{\beta}_{\text {BEER } 1}+\hat{\beta}_{\text {BEER2 }}$

$$
\begin{aligned}
& \mathrm{X}_{\mathrm{i}}=\left[\ln \left(\mathrm{P}_{\mathrm{BEERi}}\right) \mathrm{X}_{\mathrm{Oi}}\right] \\
& \hat{\beta}^{\prime}=\left[\hat{\beta}_{1}^{\prime} \hat{\beta}_{2}^{\prime}\right] \text { denotes the conventional two part estimator of } \hat{\beta}^{\prime}=\left[\hat{\beta}_{1}^{\prime} \hat{\beta}_{2}^{\prime}\right] \text {, and } \\
& \hat{\beta}_{1}^{\prime}=\left[\hat{\beta}_{\mathrm{BEER} 1} \hat{\beta}_{\mathrm{O} 1}^{\prime}\right] \text {, and } \hat{\beta}_{2}^{\prime}=\left[\hat{\beta}_{\mathrm{BEER} 2} \hat{\beta}_{\mathrm{O} 2}^{\prime}\right] .
\end{aligned}
$$

Using general results found in Terza (2012), we can show that the asymptotic variance of (A-4) can be consistently estimated using

\footnotetext{
${ }^{32}$ This is the conventionally accepted form for the conditional expectation of the outcome given the covariates in the two-part model (e.g. see, for example, Mullahy, 1998). See Duan et al. $(1982,1983)$ for a detailed discussion of smearing.
} 


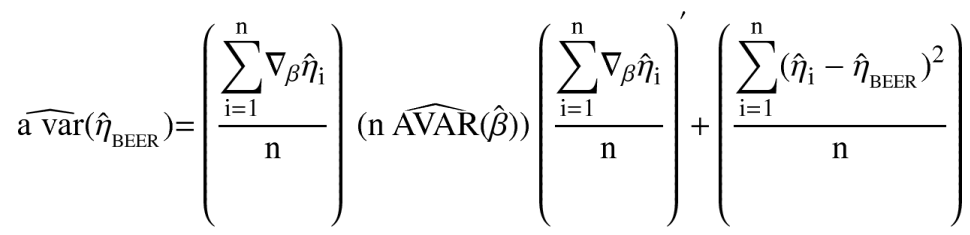

where

$$
\begin{aligned}
& \nabla_{\beta} \hat{\eta}_{i}=\left[\nabla_{\beta_{\text {BEER } 1}} \hat{\eta}_{i} \nabla_{\beta_{1 o}} \hat{\eta}_{i} \nabla_{\beta \text { BEER } 2} \hat{\eta}_{i} \nabla_{\beta_{2 o}} \hat{\eta}_{i}\right] \\
& \nabla_{\beta_{B E E R 1}} \hat{\eta}_{i}=1-\lambda\left(X_{i} \hat{\beta}_{1}\right) \hat{\beta}_{\text {BEER } 1} \ln \left(\mathrm{P}_{\text {BEERi }}\right)-\Lambda\left(\mathrm{X}_{\mathrm{i}} \hat{\beta}_{1}\right) \\
& \nabla_{\beta_{10}} \hat{\eta}_{\mathrm{i}}=-\lambda\left(\mathrm{X}_{\mathrm{i}} \hat{\beta}_{1}\right) \hat{\beta}_{\mathrm{BEER} 1} \mathrm{X}_{\mathrm{oi}} \\
& \nabla_{\beta 2 p} \hat{\eta}_{i}=1 \\
& \nabla_{\beta_{\text {BEER } 1}} \hat{\eta}_{i}=0 \text { (a vector of the same column dimension as } X_{o} \text { ) }
\end{aligned}
$$

and $\widehat{A V A R}(\hat{\beta})$ is the estimated asymptotic covariance matrix of $\hat{\beta}$ (the block diagonal matrix whose upper left-hand block is the estimated asymptotic covariance matrix of $\hat{\beta}_{1}$ and whose

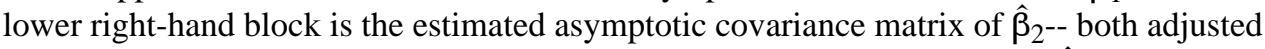
so as to be robust to potential state-level clustering effects).33 In summary, $\hat{\eta}_{\mathrm{BEER}}$ is consistent and

$$
\sqrt{\frac{\mathrm{n}}{\widehat{\operatorname{avar}}\left(\hat{\eta}_{\mathrm{BEER}}\right)}}\left(\hat{\eta}_{\mathrm{BEER}}-\eta_{\mathrm{BEER}}\right) \stackrel{\mathrm{d}}{\rightarrow} \mathrm{n}(0,1)
$$

\section{A.2 Asymptotic Standard Error and t-stat for the Intensive Margin Elasticity Estimator (3)}

From the derivation of (A-3) above, the population elasticity measure for the intensive margin is

$$
\eta_{\mathrm{BEER}(1)}=(1-\mathrm{H}) \beta_{\mathrm{BEER} 1} \quad(\mathrm{~A}-7)
$$

The corresponding sample analog elasticity estimator is (3). We can re-write (3) as

$$
\hat{\eta}_{\text {BEER(1) }}=\sum_{\mathrm{i}=1}^{\mathrm{n}} \frac{1}{\mathrm{n}} \hat{\eta}_{(1) \mathrm{i}} \quad(\mathrm{A}-8)
$$

where $\hat{\eta}_{(1) \mathrm{i}}=\eta_{1}\left(X_{\mathrm{i}}, \hat{\beta}\right)=\hat{\beta}_{\mathrm{BEER} 1}-\Lambda\left(\mathrm{X}_{\mathrm{i}} \hat{\beta}_{1}\right) \hat{\beta}_{\mathrm{BEER} 1}$. Using Terza (2012), we have that the asymptotic variance of $(\mathrm{A}-8)$ can be estimated using and $\operatorname{AVAR}\left(\hat{\beta}_{1}\right)$ is the asymptotic covariance matrix of $\hat{\beta}_{1}$ (adjusted so as to be robust to potential state-level clustering effects). The asymptotic variance given in (A-12) can be consistently estimated using

\footnotetext{
${ }^{33}$ We highlight the "n" premultiplying $\widehat{\operatorname{AVAR}}(\hat{\beta})$ in A-7, since this premultiplication is required when this matrix is obtained from packaged regression software.
} 


$$
\widehat{\operatorname{avar}}\left(\hat{\eta}_{\operatorname{BEER}(1)}\right)=\left(\frac{\sum_{\mathrm{i}=1}^{\mathrm{n}} \nabla_{\beta_{1}} \hat{\eta}_{1 \mathrm{i}}}{\mathrm{n}}\right)\left(\mathrm{n} \widehat{\left.\operatorname{AVAR}\left(\hat{\beta}_{1}\right)\right)}\left(\frac{\sum_{\mathrm{i}=1}^{\mathrm{n}} \nabla_{\beta_{1}} \hat{\eta}_{1 \mathrm{i}}}{\mathrm{n}}\right)^{\prime}+\left(\frac{\sum_{\mathrm{i}=1}^{\mathrm{n}}\left(\hat{\eta}_{1 \mathrm{i}}-\hat{\eta}_{\mathrm{BEER}(1)}\right)^{2}}{\mathrm{n}}\right)\right.
$$

where

$$
\begin{aligned}
& \nabla_{\beta_{1}} \hat{\eta}_{1 \mathrm{i}}=\left[\nabla_{\beta_{\text {BEER } 1}} \hat{\eta}_{1 \mathrm{i}} \nabla_{\beta_{1 \mathrm{o}}} \hat{\eta}_{1 \mathrm{i}}\right] \\
& \nabla_{\beta_{\text {BEER } 1}} \hat{\eta}_{1 \mathrm{i}}=1-\lambda\left(\mathrm{X}_{\mathrm{i}} \hat{\beta}_{1}\right) \hat{\beta}_{\text {BEER } 1} \ln \left(\mathrm{P}_{\mathrm{BEERi}}\right)-\Lambda\left(\mathrm{X}_{\mathrm{i}} \hat{\beta}_{1}\right) \\
& \nabla_{\beta_{1 \mathrm{o}}} \hat{\eta}_{1 \mathrm{i}}=-\lambda\left(\mathrm{X}_{\mathrm{i}} \hat{\beta}_{1}\right) \hat{\beta}_{\text {BEER } 1} \mathrm{X}_{\mathrm{oi}}
\end{aligned}
$$

and $\widehat{A V A R}\left(\hat{\beta}_{1}\right)$ is the estimated asymptotic covariance matrix of $\hat{\beta}_{1}$ (adjusted so as to be robust to potential state-level clustering effects).34 In summary, $\hat{\eta}_{\mathrm{BEER}(1)}$ is consistent and

$$
\sqrt{\frac{\mathrm{n}}{\widehat{\operatorname{avar}\left(\hat{\eta}_{\mathrm{BEER}(1)}\right)}}}\left(\hat{\eta}_{\mathrm{BEER}(1)}-\eta_{\mathrm{BEER}(1)}\right) \stackrel{\mathrm{d}}{\rightarrow} \mathrm{n}(0,1)
$$

\section{Appendix B \\ Bias in the ACCRA Beer Price Elasticity Estimates Due to Measurement Error}

Suppose the measurement error in beer price takes the general form

$$
\mathrm{ME}=\gamma_{1}+\mathrm{P}_{\mathrm{BEER}} \gamma_{\mathrm{BEER}}+\zeta \quad(\mathrm{B}-1)
$$

where $P_{\text {BEER }}$ denotes the true (but unobserved) price of beer, the $\gamma s$ are unknown parameters, and $\zeta$ is a random term. Expression (B-1) comports with "classical" measurement error if $\gamma_{\mathrm{BEER}}=0$ and $\gamma_{1}=-\mathrm{E}[\zeta]$ (Wooldridge, 2010, p.80). In this case, we expect to observe classical attenuation bias (downward bias in the absolute value) in the beer price coefficient estimate in the levels component of the two-part model- $\hat{\beta}_{\text {BEER2 }}$ in equation (2) - because it is produced via conventional log-linear OLS regression. The case for classical attenuation bias in the price coefficient estimate in the hurdle component of the model is less clear. Using simulated data, Edgerton and Jochumzen (2003) show that the classical attenuation bias argument is likely to hold in the probit model. Our two-part model specifies the hurdle component as a logit (rather than probit) model, but the simulation results of Edgerton and Jochumzen (2003) are also likely to apply here. Therefore, if measurement error were classical (i.e. if $\gamma_{\mathrm{BEER}}=0$ and $\gamma_{1}=-\mathrm{E}[\zeta]$ ), we expect the attenuation bias to manifest in the overall and extensive margin beer price elasticity estimates defined in (2) and (3), respectively.

The beer demand elasticities we estimate using the ACCRA prices (which are likely to be measured with uniformly positive error) are substantially larger in absolute value than the more stable results obtained using the UPC data. Since, this runs counter to the expectation of attenuation bias in the presence of classical measurement error, we suspect that in our case measurement error is not classical -i.e., $\gamma_{\text {BEER }} \neq 0$. For example, because the ACCRA

\footnotetext{
${ }^{34}$ In (A-9), we have highlighted the "n" premultiplying $\widehat{\operatorname{AVAR}}\left(\hat{\beta}_{1}\right)$ for the same reasons as with (A-5).
} 
price is based on a single high quality brand (Heineken), it is likely to be high across observations relative to the true price for the sampled unit, so that the measurement error is likely to be negatively correlated with the true price-i.e., $\gamma_{\mathrm{BEER}}<0$. To investigate whether such a negative correlation might produce estimation results consistent with those we obtained for (2) and (3), we simulated data using the following sampling design

Hurdle

$$
\mathrm{H}=\mathrm{I}\left(\alpha_{11}+\mathrm{P}_{\mathrm{BEER}} \alpha_{12}+\mathrm{X}_{\mathrm{o}} \alpha_{13}+v>0\right) \quad(\mathrm{B}-2)
$$

Levels

$$
\mathrm{Y}^{\ell}=\exp \left(\alpha_{21}+\mathrm{P}_{\mathrm{BEER}} \alpha_{22}+\mathrm{X}_{\mathrm{o}} \alpha_{23}+\varepsilon\right) \quad(\mathrm{B}-3)
$$

where

$\mathrm{H}=$ the binary hurdle variable defined for the full population

$\mathrm{I}(\mathrm{C})$ denotes the indicator function $=1$ if condition $\mathrm{C}$ holds, 0 otherwise.

$\mathrm{P}_{\mathrm{BEER}}=\max \mathrm{P}_{\mathrm{BEER}} \times \mathrm{U}(0,1)=$ the true price of beer

$\max \mathrm{P}_{\mathrm{BEER}}=$ maximum beer price $($ a simulation parameter to be specified)

$\mathrm{U}(0,1)=$ uniform pseudo random variable on the unit interval

$\mathrm{X}_{\mathrm{O}}=\max \mathrm{X}_{\mathrm{O}} \times \mathrm{U}(0,1)=$ the value of a control variable

$\max X_{\mathrm{o}}=$ maximum value of the control variable (a simulation parameter to be specified)

$v=\ln \left(\frac{\delta}{1-\delta}\right)=$ the logistic error term for the hurdle [where $\delta=\mathrm{U}(0,1)$ ]

$\mathrm{Y}^{\ell}=$ the levels value of alcohol demand (defined only for those for whom $\mathrm{H}=1$ )

$\varepsilon \sim \mathrm{n}\left(0, \sigma^{2}\right)=$ [normally distributed with mean 0 and variance $\sigma^{2}$ ]

and the $a$ 's and $\sigma^{2}$ are all simulation parameters to be specified. Our choices for the simulation parameter values are:

$$
\begin{aligned}
& \max P_{B E E R}=1, \max X_{0}=.5 \\
& a_{11}=2.5, a_{12}=-1, a_{13}=1.5 \\
& a_{21}=2, a_{22}=-1, a_{23}=1.25 \\
& \sigma^{2}=4 .
\end{aligned}
$$

After simulating a sample of size 10,000 using the above sampling design, we generated the observed (with measurement error) beer price value as

$$
\mathrm{P}_{\mathrm{BEER}}^{*}=\mathrm{P}_{\mathrm{BEER}}+\mathrm{ME}
$$

where ME is defined in (B-1) with $\gamma_{1}=1, \gamma_{\mathrm{BEER}}=-.75$ (producing a negative correlation between ME and the true price of beer), and $\zeta=\max \zeta \times \mathrm{U}(0,1)$ with $\max \zeta=.35$. To complete the simulation exercise we estimated the parameters of (B-2) with $\mathrm{P}_{\mathrm{BEER}}$ replaced with $\mathrm{P}_{\mathrm{BEER}}^{*}$ by applying conventional logit analysis to the full sample. Similarly, we estimated the parameters of (B-3) via OLS, applied to the subsample for whom $\mathrm{H}=1$. 
The results in Table B.1 demonstrate that it is possible to obtain upwardly biased estimates of the effect of beer price in both parts of the two-part model if measurement error is negatively correlated with the true beer price (specifically, if $\gamma_{\text {BEER }}<0$ ).

\section{Table B.1}

Simulation Estimation Results: Non-Classical Measurement Error

\begin{tabular}{|l|l|l|}
\hline Variable & Coefficient Estimate & t-stat \\
\hline \multicolumn{3}{|l|}{ Hurdle } \\
\hline $\mathrm{P}_{\text {BEER }}^{*}$ & -1.83 & -6.54 \\
\hline $\mathrm{X}_{\mathrm{O}}$ & 1.21 & 5.06 \\
\hline Intercept & 4.37 & 11.63 \\
\hline Levels & \multicolumn{2}{|l}{} \\
\hline $\mathrm{P}_{\mathrm{BEER}}^{*}$ & -1.15 & -6.72 \\
\hline $\mathrm{X}_{\mathrm{O}}$ & .928 & 6.29 \\
\hline Intercept & 3.06 & 13.53 \\
\hline
\end{tabular}

For the purpose of comparison, we re-sampled and re-estimated the model under the classical measurement error assumption that $\gamma_{\mathrm{BEER}}=0$ and $\gamma_{1}=-\max \zeta / 2$. The results displayed in Table B.2 are consistent with classical attenuation bias, whereas those in B.1 are not.

Table B.2

Simulation Estimation Results: Classical Measurement Error

\begin{tabular}{|l|l|l|}
\hline Variable & Coefficient Estimate & t-stat \\
\hline \multicolumn{3}{|l|}{ Hurdle } \\
\hline $\mathrm{P}_{\text {BEER }}^{*}$ & -.849 & -7.21 \\
\hline $\mathrm{X}_{\mathrm{O}}$ & 1.24 & 4.98 \\
\hline Intercept & 2.50 & 26.41 \\
\hline Levels & \multicolumn{2}{|l}{} \\
\hline $\mathrm{P}_{\text {BEER }}^{*}$ & -.908 & -13.14 \\
\hline $\mathrm{X}_{\mathrm{O}}$ & 1.18 & 7.94 \\
\hline Intercept & 1.99 & 36.28 \\
\hline
\end{tabular}

\section{Literature Cited}

Arcidiacono P, Sieg H, Sloan F. Living Rationally Under The Volcano? An Empirical Analysis Of Heavy Drinking And Smoking. International Economic Review. 2007; 48(1):37-65.

Benson BL, Rasmussen DW, Zimmerman PR. Implicit taxes collected by state liquor monopolies. Public Choice. 2003; 115(3-4):313-331.

Bray JW, Loomis BR, Engelen M. Correlates of In-Store Promotions for Beer: Differential Effects of Market and Product Characteristics. Journal of Studies on Alcohol and Drugs. 2007; 68(2):220-227. [PubMed: 17286340] 
Bray JW, Loomis BR, Engelen M. You Save Money When You Buy in Bulk: Does Volume-Based Pricing Cause People to Buy More Beer? Health Economics. 2009; 18(5):607-618. [PubMed: 18770524]

Chaloupka FJ, Saffer H, Grossman M. Alcohol-control Policies and Motor Vehicle Fatalities. Journal of Legal Studies. 1993; 22(1):161-186.

Chaloupka FJ, Grossman M, Saffer H. The Effects of Price on Alcohol Consumption and AlcoholRelated Problems. Alcohol Res Health. 2002; 26(1):22-34. [PubMed: 12154648]

Chen, CM.; Yi, H-y; Falk, DE.; Stinson, FS.; Dawson, DA.; Grant, BF. Alcohol Use and Alcohol Use Disorders in the United States: Main findings from the 2001-2002 National Epidemiologic Survey on Alcohol and Related Conditions (NESARC). Bethesda, MD: National Institute on Alcohol Abuse and Alcoholism, National Institutes of Health; 2006 Jan.

Coate D, Grossman M. Effects of Alcoholic Beverage Prices and Legal Drinking Ages on Youth Alcohol Use. Journal of Law and Economics. 1988; 31(1):145-171.

Cook, PJ. Paying the Tab: The Costs and Benefits of Alcohol Control. Princeton, NJ: Princeton University Press; 2007.

Dave D, Kaestner R. Alcohol Taxes and Labor Market Outcomes. Journal of Health Economics. 2002; 21(3):357-371. [PubMed: 12022263]

Dawson DA, Goldstein RB, Grant BF. Rates and Correlates of Relapse Among Individuals in Remission from DSM-IV Alcohol Dependence: A 3-year Follow-up. Alcohol ClinExp Res. 2007; (12):2036-2045.

Duan N. Smearing Estimate: A Nonparametric Retransformation Method. Journal of the American Statistical Association. 1983; 78:605-610.

Duan, N.; Manning, WG.; Morris, CN.; Newhouse, JP. R-2754-HHS. Santa Monica, California: The Rand Corporation; 1982. A Comparison of Alternative Models for the Demand for Medical Care.

Duan N, Manning WGJ, Morris CN, Newhouse JP. A Comparison of Alternative Models for the Demand for Medical Care. Journal of Business and Economic Statistics. 1983; 1:115-126.

Edgerton, D.; Jochumzen, P. Working Paper WP. Vol. 2003. Lund University; 2003. Estimation in Binary Choice Models with Measurement Error; p. 4

Farrell S, Manning WG, Finch MD. Alcohol Dependence and the Price of Alcoholic Beverages. J Health Econ. 2003; 22:117-147. [PubMed: 12564720]

Freeman DG. Alternative Panel Estimates of Alcohol Demand, Taxation and the Business Cycle. Southern Economic Journal. 2000; 67(2):325-344.

Grant, BF.; Kaplan, K.; Shepard, J.; Moore, T. Source and Accuracy Statement for Wave 1 of the 2001-2002 National Epidemiologic Survey on Alcohol and Related Conditions. Bethesda, MD: National Institute on Alcohol Abuse and Alcoholism; 2003.

Giesbrecht N, Greenfield TK, Anglin L, Johnson S. Changing the Price of Alcohol in the United States: Perspectives from the Alcohol Industry, Public Health, and Research. Contemporary Drug Problems. 2004; 31(4):711-736.

Giesbrecht NA, Greenfield TK. Preventing alcohol-related problems in the US through policy: media campaigns, regulatory approaches and environmental interventions. Journal of Primary Prevention. 2003; 24(1):63-104.

Grossman M, Chaloupka FJ, Sirtalan I. An Empirical Analysis of Alcohol Addiction: Results from the Monitoring the Future Panels. Economic Inquiry. 1998; 36(1):39-48.

Grossman, M.; Coate, D.; Arluck, GM. Price Sensitivity of Alcoholic Beverages in the United States. In: Moore, MH.; Gerstien, DR., editors. Control Issues in Alcohol Abuse Prevention: Strategies for states and Communities. Greenwich, CT: JAI Press; 1987. p. 169-198.

Kenkel DS. New Estimates of the Optimal Tax on Alcohol. Economic Inquiry. 1996; 34(2):296-319.

Kenkel DS. Drinking, Driving and Deterrence: The Effectiveness and Social Costs of Alternative Policies. Journal of Law and Economics. 1993; 36(2):877-913.

Kerr, WC. Ethanol content of beer sold in the U.S.: variation over time, across states and by individual drinks. In: Preedy, VR.; Watson, RR., editors. Encyclopedia Handbook of Beer in Health and Disease Prevention. London: Academic Press (Elsevier); 2008. p. 255-264. 
Laixuthai A, Chaloupka FJ. Youth Alcohol Use and Public Policy. Contemporary Policy Issues. 1993; 11(4):70-81.

Leung, SF.; Phelps, CE. A Review of Estimates of the Price Sensitivity of Demand for Alcoholic Beverages. In: Hilton, ME.; Bloss, G., editors. Economics and the Prevention of Alcohol-related Problems. Bethesda, MD: National Institute on Alcohol Abuse and Alcoholism; 1993. p. 123-148.NIAAA Research Monograph 25, NIH Pub. No. 95-3513.

Manning WG, Blumberg L, Moulton LH. The Demand for Alcohol: the Differential Response to Price. Journal of Health Economics. 1995; 14(2):123-148. [PubMed: 10154654]

Markowitz S, Kaestner R, Grossman M. An Investigation of the Effects of Alcohol Consumption and Alcohol Policies on Youth Risky Sexual Behaviors. American Economic Review. 2005; 95(2): 263-266.

Mullahy J. Much Ado about Two: Reconsidering Retransformation and the Two-part Model in Health Econometrics. Journal of Health Economics. 1998; 17:247-281. [PubMed: 10180918]

National Institute on Alcohol Abuse and Alcoholism. [accessed June 18, 2010] Apparent Per Capita Ethanol Consumption for the United States, 1850-2007. 2010. http://www.niaaa.nih.gov/ Resources/DatabaseResources/QuickFacts/AlcoholSales/consum01.htm

Pennsylvania Liquor Control Board. [accessed March 18, 2012] What Licensees Should Know about Act of 2011.pdf. 2011. http://www.portal.state.pa.us/portal/server.pt? open $=514 \&$ objID $=611770 \&$ mode $=2$

Ruhm CJ. Alcohol Policies and Highway Vehicle Fatalities. Journal of Health Economics. 1996; 15(4):435-454. [PubMed: 10164038]

Sloan FA, Reilly FA, Schenzler C. Effects of Prices, Civil and Criminal Sanctions, and Law Enforcement on Alcohol-Related Mortality. Journal of Studies on Alcohol. 1994; 55(4):454-465. [PubMed: 7934053]

Terza, JV. Department of Economics, University of North Carolina at Greensboro; 2012. Correct Standard Errors for Multi-Stage Regression-Based Estimators: A Practitioner's Guide with Illustrations. Unpublished Manuscript

Wagenaar A, Salois MJ, Komro KA. Effects of Beverage Alcohol Price and Tax Levels on Drinking: A Meta-Analysis of 1003 Estimates from 112 Studies. Addiction. 2009; 104(2):179-190. [PubMed: 19149811]

Williams J, Chaloupka FJ, Wechsler H. Are There Differential Effects of Price and Policy on College Students 'Drinking Intensity? Contemporary Economic Policy. 2005; 23(1):78-90.

Wooldridge, J. Econometric Analysis of Cross Section and Panel Data. 2nd Edition. Cambridge, MA: MIT Press; 2010.

Young, DJ. Alcohol Taxes, Beverage Prices, Drinking and Traffic Fatalities in Montana, mimeo. University of Montana; 2010 Jan.

Young DJ, Bielinska-Kwapisz A. Alcohol Consumption, Beverage Prices and Measurement Error. Journal of Studies on Alcohol. 2003; 64(2):235-238. [PubMed: 12713197]

Young DJ, Bielinska-Kwapisz A. Alcohol Taxes and Beverage prices. National Tax Journal. 2002; 55(1):57-73. 


\begin{tabular}{|c|c|c|c|c|c|c|c|c|c|c|c|c|c|c|c|c|}
\hline & $\begin{array}{l}\text { UNIVERSAL } \\
\text { PRODUCT } \\
\text { CODE }\end{array}$ & $\begin{array}{l}\text { BRAND } \\
\text { DESCRIP- } \\
\text { TION }\end{array}$ & SIZE & $\begin{array}{c}\text { PRO- } \\
\text { DUCT } \\
\text { MODULE }\end{array}$ & STYLE & TYPE & $\begin{array}{l}\text { BOTTLE } \\
\text { TYPE }\end{array}$ & $\begin{array}{c}\text { CONTAIN- } \\
\text { ER }\end{array}$ & $\begin{array}{l}\text { DOL- } \\
\text { LAR } \\
\text { SALES }\end{array}$ & $\begin{array}{l}\text { DOL- } \\
\text { LAR } \\
\text { SHARE }\end{array}$ & $\begin{array}{c}\text { EQ UNIT } \\
\text { SALES }\end{array}$ & \begin{tabular}{|c|} 
EQ \\
SHARE
\end{tabular} & $\begin{array}{l}\text { UNIT } \\
\text { SALES }\end{array}$ & $\begin{array}{l}\text { UNIT } \\
\text { SHARE }\end{array}$ & \begin{tabular}{|c} 
AVE- \\
RAGE \\
SELLIN \\
G PRICE \\
\end{tabular} & \begin{tabular}{|c} 
AVER- \\
AGE EQ \\
SELLIN \\
G PRICE
\end{tabular} \\
\hline $\begin{array}{l}\text { TOTAL } \\
\text { BUDWEISER }\end{array}$ & & BUDWEISER & & BEER & & & & & $2,585,321$ & 12.8 & 161,193 & 12.1 & 362,954 & 13.4 & 7.12 & 16.04 \\
\hline \begin{tabular}{l|} 
BUDWEISER \\
BR NRB LN 24P \\
$12 \mathrm{OZ}$ \\
\end{tabular} & 001820011349 & BUDWEISER & 12.00 & BEER & DOMESTIC & REGULAR & LONGNECK & \begin{tabular}{|c|} 
NON \\
REFILLAB \\
LE BOTTLE \\
\end{tabular} & 104,593 & 0.5 & 7,096 & 0.5 & 7,096 & 0.3 & 14.74 & 14.74 \\
\hline $\begin{array}{l}\text { BUDWEISER } \\
\begin{array}{ll}\mathrm{BR} \quad \mathrm{CN} & 6 \mathrm{P} \\
12 \mathrm{OZ} & \end{array} \\
\end{array}$ & 001820000016 & BUDWEISER & 12.00 & BEER & DOMESTIC & REGULAR & N/A & CAN & 123,518 & 0.6 & 6,263 & 0.5 & 25,056 & 0.9 & 4.93 & 19.72 \\
\hline 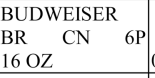 & 001820000018 & BUDWEISER & 16.00 & BEER & DOMESTIC & REGULAR & N/A & CAN & 29,092 & 0.1 & 1,630 & 0.1 & 4,891 & 0.2 & 5.95 & 17.85 \\
\hline $\begin{array}{l}\text { BUDWEISER } \\
\text { BR NRB LN } \\
16 \mathrm{OZ}\end{array}$ & 001820000024 & BUDWEISER & 16.00 & BEER & DOMESTIC & REGULAR & LONGNECK & \begin{tabular}{|c|} 
NON \\
REFILLAB \\
LE BOTTLE \\
\end{tabular} & 0 & 0.0 & 0 & 0.0 & 0 & 0.0 & 0.00 & 0.00 \\
\hline 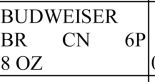 & 001820000042 & BUDWEISER & 8.000 & BEER & DOMESTIC & REGULAR & $\mathrm{N} / \mathrm{A}$ & CAN & 11,457 & 0.1 & 443 & 0.0 & 2,659 & 0.1 & 4.31 & 25.86 \\
\hline \begin{tabular}{|l|l|} 
BUDWEISER \\
$\mathrm{BR}$ & $\mathrm{NRB}$ \\
$40 \mathrm{OZ}$ & \\
\end{tabular} & 001820000116 & BUDWEISER & 40.00 & BEER & DOMESTIC & REGULAR & REGULAR & \begin{tabular}{|c|} 
NON \\
REFILLAB \\
LE BOTTLE \\
\end{tabular} & 0 & 0.0 & 0 & 0.0 & 0 & 0.0 & 0.00 & 0.00 \\
\hline \begin{tabular}{|ll|}
\multicolumn{3}{l|}{ BUDWEISER } \\
BR & NRB \\
$40 \mathrm{OZ}$ & \\
\end{tabular} & 001820000126 & BUDWEISER & 40.00 & BEER & DOMESTIC & REGULAR & REGULAR & \begin{tabular}{|c|} 
NON \\
REFILLAB \\
LE BOTTLE \\
\end{tabular} & 46,991 & 0.2 & 2,902 & 0.2 & 20,903 & 0.8 & 2.25 & 16.19 \\
\hline \begin{tabular}{|l|} 
BUDWEISER \\
BR \\
$24 \mathrm{OZ}$ \\
\end{tabular} & 001820000466 & BUDWEISER & 24.00 & BEER & DOMESTIC & REGULAR & N/A & CAN & 50,926 & 0.3 & 3,288 & 0.2 & 39,452 & 1.5 & 1.29 & 15.49 \\
\hline $\begin{array}{l}\text { BUDWEISER } \\
\mathrm{BR} \quad \mathrm{NRB} \quad \mathrm{LN} \\
22 \mathrm{OZ}\end{array}$ & 001820000478 & BUDWEISER & 22.00 & BEER & DOMESTIC & REGULAR & LONGNECK & \begin{tabular}{|c|} 
NON \\
REFILLAB \\
LE BOTTLE \\
\end{tabular} & 51,569 & 0.3 & 3,067 & 0.2 & 40,140 & 1.5 & 1.28 & 16.81 \\
\hline $\begin{array}{l}\text { BUDWEISER } \\
\mathrm{BR} \quad \mathrm{CN} \quad 24 \mathrm{P} \\
12 \mathrm{OZ}\end{array}$ & 001820000639 & BUDWEISER & 12.00 & BEER & DOMESTIC & REGULAR & N/A & CAN & 246,531 & 1.2 & 16,126 & 1.2 & 16,126 & 0.6 & 15.29 & 15.29 \\
\hline $\begin{array}{l}\text { BUDWEISER } \\
\text { BR NRB LN 12P } \\
12 \mathrm{OZ}\end{array}$ & 001820000771 & BUDWEISER & 12.00 & BEER & DOMESTIC & REGULAR & LONGNECK & \begin{tabular}{|c|} 
NON \\
REFILLAB \\
LE BOTTLE \\
\end{tabular} & 308,351 & 1.5 & 19,111 & 1.4 & 38,222 & 1.4 & 8.07 & 16.13 \\
\hline $\begin{array}{l}\text { BUDWEISER } \\
\text { BR NRB LN } 6 \mathrm{P} \\
7 \mathrm{OZ}\end{array}$ & 001820000774 & BUDWEISER & 7.000 & BEER & DOMESTIC & REGULAR & LONGNECK & \begin{tabular}{|c|} 
NON \\
REFILLAB \\
LE BOTTLE \\
\end{tabular} & 2,357 & 0.0 & 97 & 0.0 & 660 & 0.0 & 3.57 & 24.30 \\
\hline $\begin{array}{l}\text { BUDWEISER } \\
\text { BR NRB LN } 6 \mathrm{P} \\
12 \mathrm{OZ}\end{array}$ & 001820000834 & BUDWEISER & 12.00 & BEER & DOMESTIC & REGULAR & LONGNECK & \begin{tabular}{|c|} 
NON \\
REFILLAB \\
LE BOTTLE \\
\end{tabular} & 97,461 & 0.5 & 4,972 & 0.4 & 19,892 & 0.7 & 4.90 & 19.60 \\
\hline
\end{tabular}

Figure 1.

SAMPLE: BUDWEISER Buffalo-Rochester, 24 WEEKS ENDING 1/01/05 (Grocery Store Sales) 


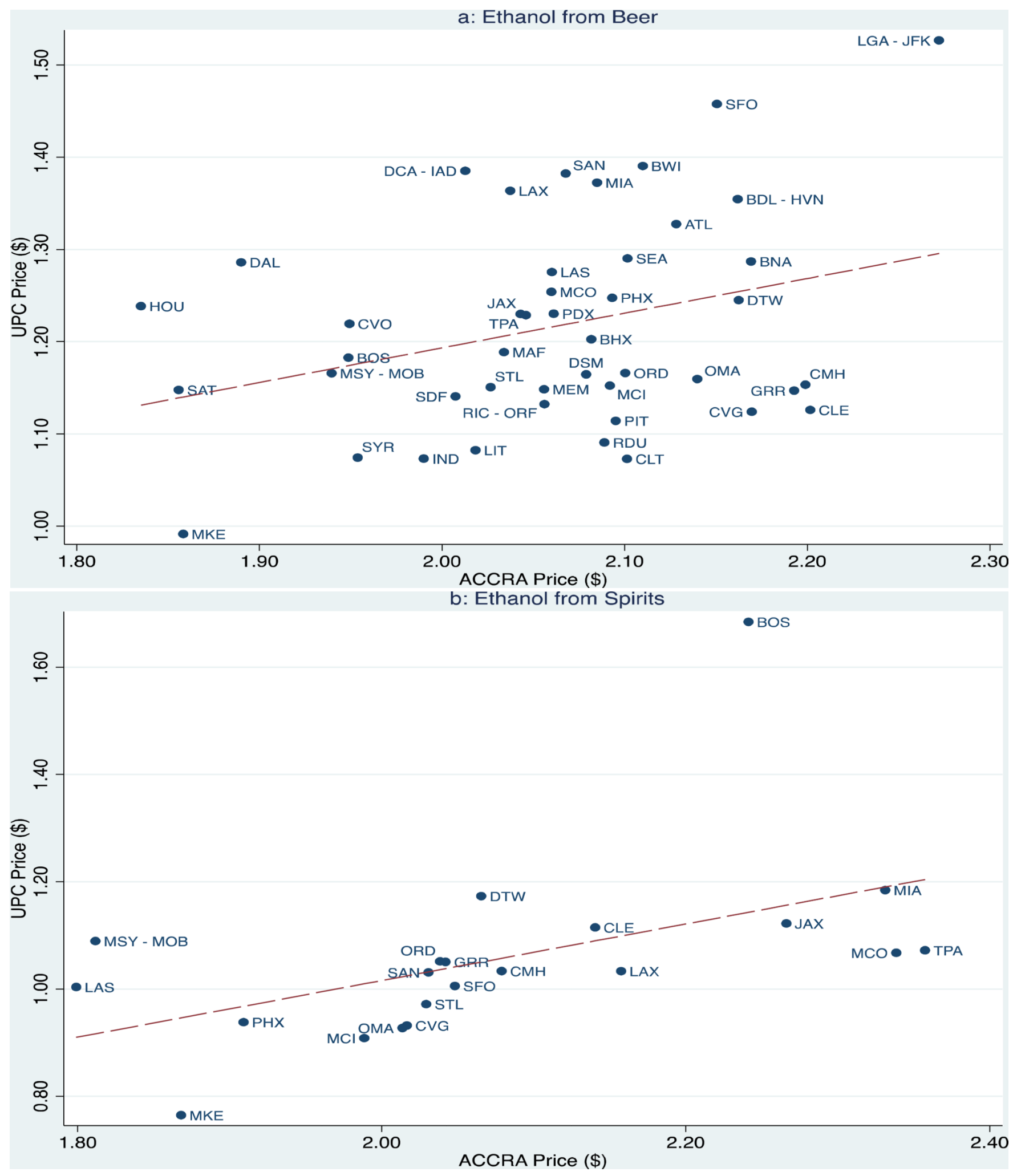

J Health Econ. Author manuscript; available in PMC 2013 December 01. 


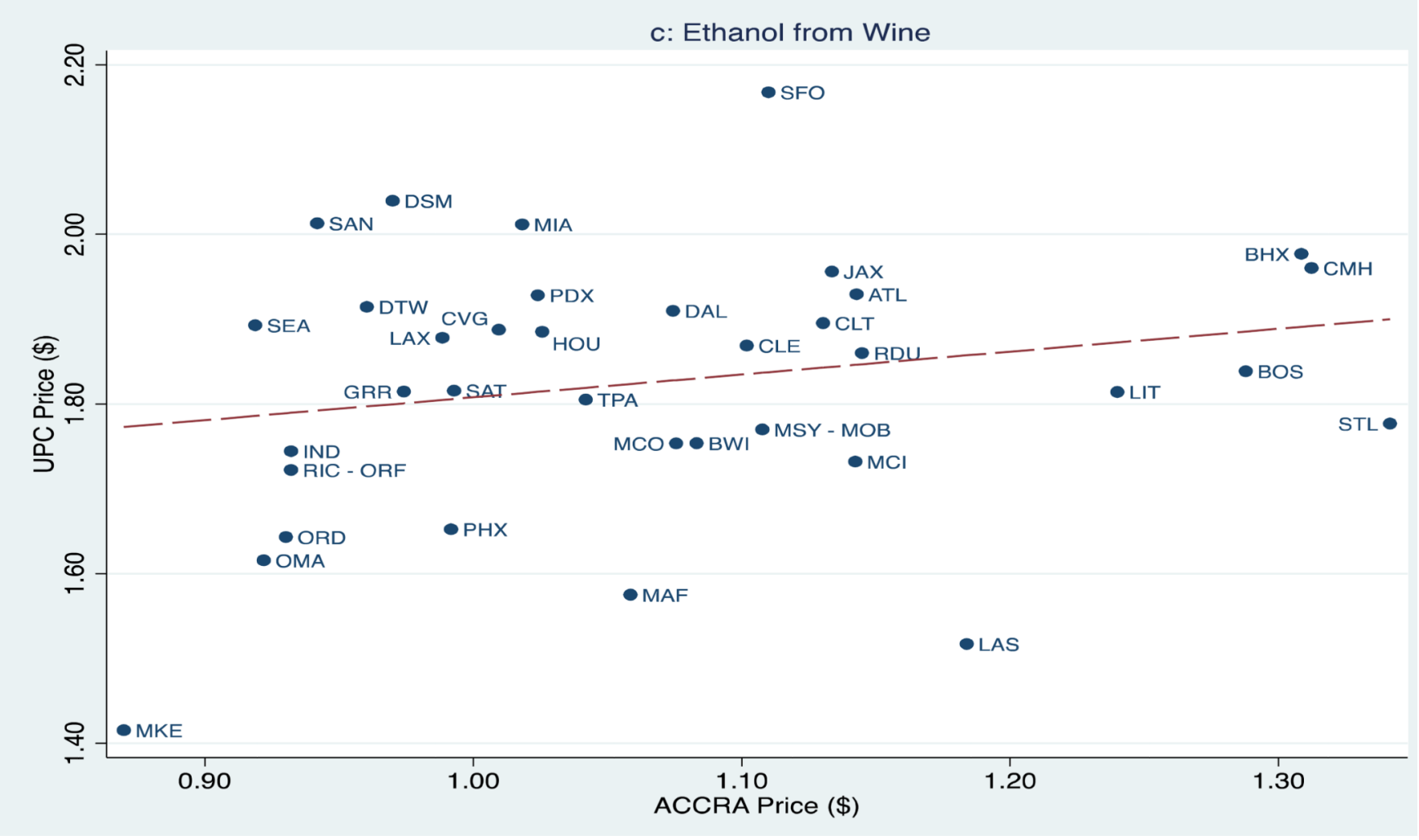

Figure 2.

Market-Specific Volume Adjusted Prices of Ethanol, 2004

Notes: Dotted line refers to regression of UPC on ACCRA prices. Abbreviations: Albany (CVO), Atlanta (ATL), Baltimore (BWI), Birmingham (BHX), Boston (BOS), Charlotte (CLT), Chicago (ORD), Cinncinnati (CVG), Cleveland (CLE), Columbus (CMH), Dallas, (DAL), Des Moines (DSM), Detroit (DTW), Grand Rapids (GRR), Hartford-New Haven (BDL-HVN), Houston (HOU), Indianapolis (IND), Jacksonville (JAX), Kansas City (MCI), Las Vegas (LAS), Little Rock (LIT), Los Angeles (LAX), Louisville (SDF), Memphis (MEM), Miami (MIA), Milwaukee (MKE), Nashville (BNA), New Orleans-Mobile (MSYMOB), New York (JFK-LGA), Omaha (OMA), Orlando (MCO), Philadelphia (PHL), Phoenix (PHX), Pittsburgh (PIT), Portland (PDX), Raleigh-Durham (RDU), RichmondNorfolk (RIC-ORF), San Antonio (SAT), San Diego (SAN), San Francisco (SFO), Seattle (SEA), St Louis (STL), Syracuse (SYR), Tampa (TPA), Washington DC (DCA-IAD), West Texas (MAF). 
$\stackrel{\bar{z}}{2} \Xi 8$

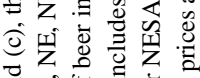

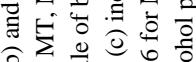

仓ิ

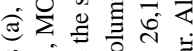

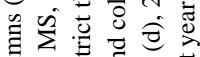

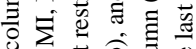

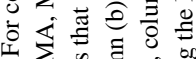

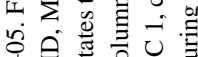

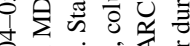

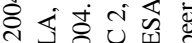

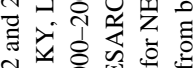

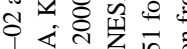

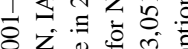

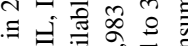

Q

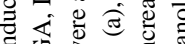

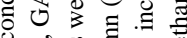

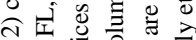

式论

嵌 :

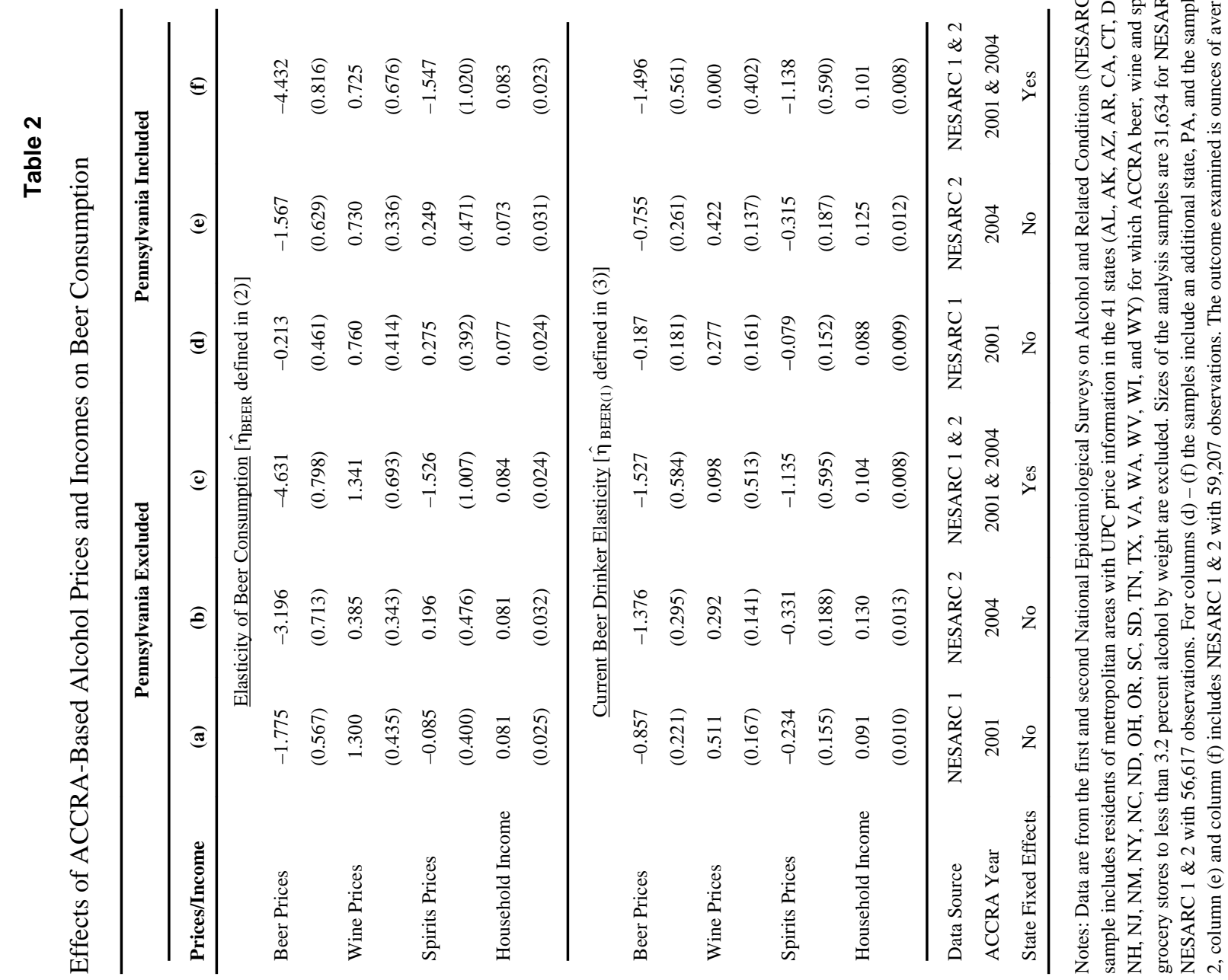




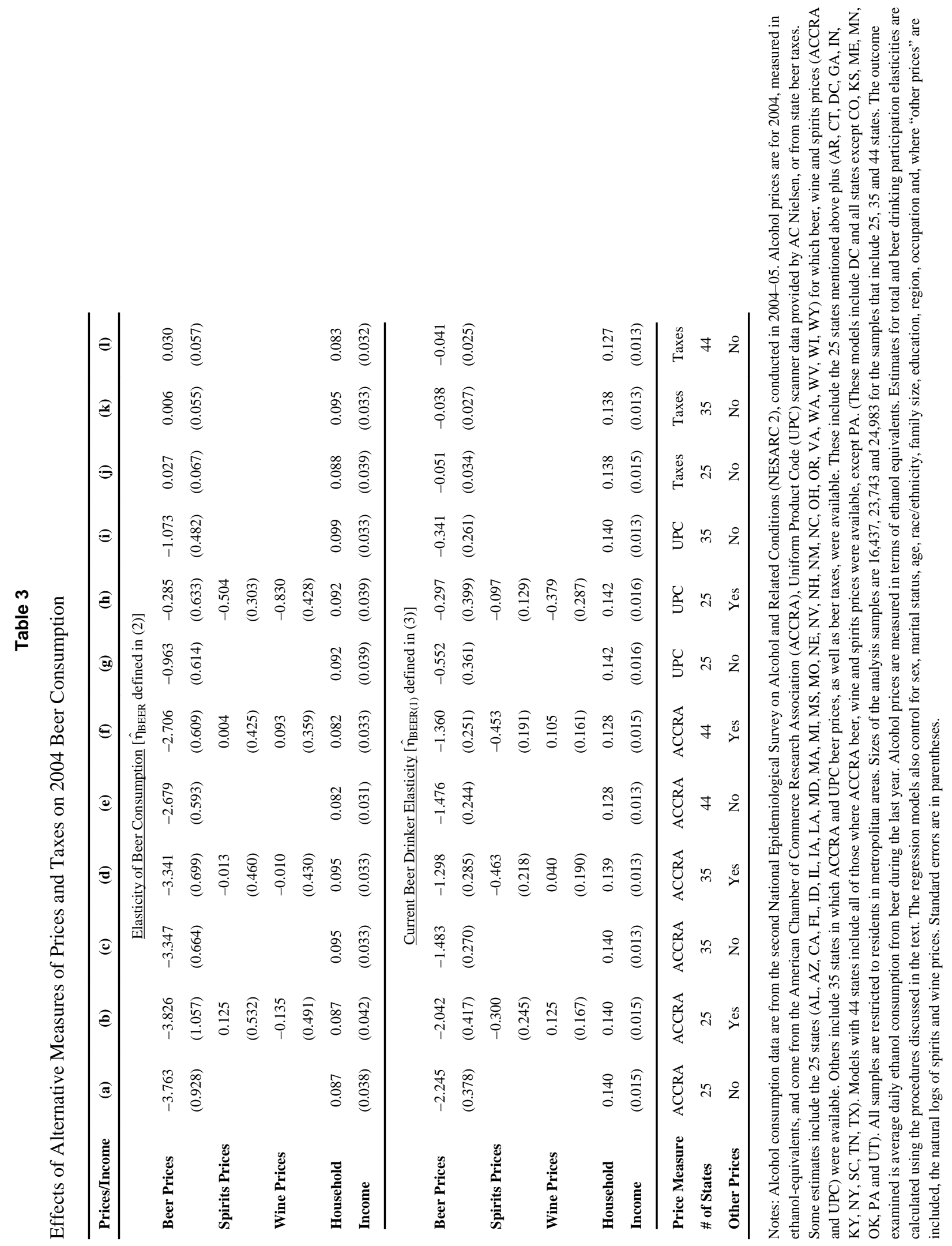

